\title{
Characteristics of distillation fractions obtained by various methods for the distillation of solid-state fermented mash by adding dried milk
}

\author{
Je Young Shin ${ }^{1}$, Heui-Yun Kang ${ }^{2}$, Seok-Tae Jeong ${ }^{2}$, Hwa Rang Seo², \\ Chang-Soo Kang ${ }^{1}$, Han-Seok Choi ${ }^{1 *}$ \\ ${ }^{1}$ Department of Agriculture \& Fisheries Processing, Korea National College of Agriculture and Fisheres, \\ Jeonju 54874, Korea \\ ${ }^{2}$ Department of Agrofood Resources, National Institute of Agricultural Science, RDA, Wanju 55365, Korea
}

\section{분유 첨가 고체발효 술덧의 증류 방법에 따른 증류 분획물의 특성}

\author{
신제영 ${ }^{1} \cdot$ 강희윤 $^{2} \cdot$ 정석태 $^{2} \cdot$ 서화랑 $^{2} \cdot$ 강창수 $^{1} \cdot$ 최한석 $^{1 *}$ \\ ${ }^{1}$ 한국농수산대학 농수산가공학과, ${ }^{2}$ 국립농업과학원 발효가공식품과
}

\begin{abstract}
To enhance the flavor of solid-state fermented spirits, the effects of powdered milk on the composition of the distillation fractions obtained by two different distillation methods were evaluated. In the solid-state fermented product, the addition of whole milk powder did not affect alcohol production. However, the addition of milk increased the amino acid content and reducing sugar content, and decreased the formic, acetic, and succinic acid contents. Distillation using a microwave was four times faster than distillation using steam; however, the resulting number of fractions was high, with a wide range of alcohol flow rates. After the addition of whole milk powder, the contents of ethyl acetate and ethyl caproate were 2 times and 16-27 times higher, respectively, in the fraction, and the contents of butyric, valeric, and hexanoic acids among the volatile organic acids increased. In addition, the content of furfural, an odor component, increased 3.45 times from $1,393.73 \mathrm{mg} / \mathrm{L}$ to $4,801.93 \mathrm{mg} / \mathrm{L}$. The microwave distillation method resulted in a 1.46-fold higher ethyl caproate content in the distillate compared with that obtained by steam distillation. However, as the temperature of the solid-state fermented mash was raised to over $300^{\circ} \mathrm{C}$, the content of furfural increased by 3.29 times. These results support the use of milk powder in distilled spirits and may guide the development of optimized methods.
\end{abstract}

Keywords : solid-state fermentation, microwave distillation, steam distillation, spirits, whole milk powder

\section{서 론}

우리나라의 주류시장 규모는 2019년 공장도가 기준 8 조 9 천억 원으로 소비자가로 환산하면 2조 원 규모에 육박하는 매우 큰 시장이다(MAFRA, 2020). 최근 양고기꼬치, 양 갈비 등 중국 음식의 인기와 2015년 한중 FTA 체결에 따른 관세
인하로 지난 10년간(2011-2020) 고량주 수입량은 1.5배, 수 입금액은 4배 증가하였다(KCS, 2021). 또한, 고급 고량주에 대한 소비자의 선호도 증가로 2013년 이후 고량주의 병당 $(500 \mathrm{~mL})$ 수입가격은 2020년까지 연평균 $13.4 \%$ 씩 상승하였 다(KCS, 2021). 주류의 수입은 술 자체의 수입뿐 아니라, 그 술을 만들기 위해 사용한 농산물의 소비도 의미한다. 곡물 1

*Corresponding author. E-mail : coldstone@korea.kr, Phone : +82-63-238-9321, Fax : +82-63-238-9329

Received 08 September 2021; Revised 10 October 2021; Accepted 14 October 2021.

Copyright (c) The Korean Society of Food Preservation.

This is an Open Access article distributed under the terms of the Creative Commons Attribution Non-Commercial License (http://creativecommons.org/licenses/by-nc/4.0) which permits unrestricted non-commercial use, distribution, and reproduction in any medium, provided the original work is properly cited. 
톤당 순 알코올 생산량 $450 \mathrm{~L}$, 고량주의 알코올 함량 $40 \%$ 로 단순 계산했을 때 2020년만 우리나라에 7천 톤 분량의 수수 가 수입되었을 것으로 추정된다. 국내 수수 생산량은 2009년 기준 2,562톤(MIFFAF, 2012)으로 고량주로 수입되는 양이 국내 생산량의 2.7 배에 상당하는 수준이다.

고량주는 주원료로 수수를 이용하며 급수 비율이 50-60\% 로 수분함량이 적은 고체 형태로 발효하는 것을 특징으로 한 다. 이러한 제조법은 술에 강렬한 향을 부여하여 소비자들의 기호를 자극한다. 국내에서도 1970 년대 3 개의 고량주 제조회 사에서 생산하였으나, 1990년대 모두 폐업하여 제조공정에 대한 비법이 모두 소실된 상태이다. 우리 수수의 이용량을 확 대하기 위해서는 고체발효 증류주를 제조하는 기술이 필요한 실정이다.

이에 본 연구팀에서는 수수를 이용한 고체발효 증류주 제조 특성에 대하여 평가하였다. 고량주는 특징적인 과일향 ethyl caproate(Lin 등, 2006)와 파인애플향 ethyl butyrate (Lin 등, 2006)를 가지고 있다고 알려져 있다. Ethyl caproate는 주로 고량주를 제조할 때 사용되는 진휽에 사는 Clostridium klyuveri 가 알코올을 대사하면서 생성되며(Yan과 Dong, 2018), ethyl butyrate은 ethanol과 butyric acid 효소 반응을 해서 만들어진 다(Yoon 등, 2017). 그러나 관련 미생물은 우리나라에서 허 용하지 않아 사용에 문제점이 있다. 이의 대책으로 본 연구팀 에서는 전지분유를 첨가하면 술덧에 ethyl caproate의 함량을 증가시킬 수 있다는 것을 발견하고 적용하였다. 또한, 증류방 법에 있어서 고체발효 술덧은 열전달이 원활하지 못해 자켓 에 스팀을 넣어 술덧의 온도를 상승시키는 간접가열방식을 사용하지 못하고 술덧 하부에 스팀을 공급하는 방식을 사용 하고 있다. 이 때문에 응축수의 발생, 열손실, 스팀의 청결 유 지와 설비 구입 등의 문제가 발생된다. 이에 대한 대안으로 전자파를 이용한 증류를 시도하였고, 기존 스팀방식과의 차 이를 비교하였다.

\section{재료 및 방법}

\section{재료 및 사용균주}

본 실험에 사용한 고체발효 술덧을 원료는 수수는 충남지 역에서 재배된 청풍수수를 사용하였으며, 누룩은 산성누룩 (Kumjung-gu, Busan, Korea)을 사용하였다. 효모는 실험실 에서 분리하여 보관 중인 Saccharomyces cerevisiae N9(Anh 등, 2014; Choi 등, 2004)을 YPD배지(BD Difco, New Jersey, $\mathrm{USA}$ )에 접종하고, $30^{\circ} \mathrm{C}$ 에서 48 시간 전배양한 후 사용하였다.

\section{고체술덧 제조}

수수를 롤밀(Kyungchang, Seoul, Korea)을 사용하여 1.5 $\mathrm{mm}$ 이하로 거칠게 분쇄하였다. 분쇄된 수수에 $40 \%$ 의 물을 첨가하고 30 분간 방치한 후 수수의 $40 \%(\mathrm{w} / \mathrm{w})$ 되는 왕겨를 혼 합한 다음 40 분간 증자하였다. 증자 후 $35^{\circ} \mathrm{C}$ 이하로 냉각하 고, 수수와 왕겨 혼합물 무게에 대하여 $10 \%$ 의 누룩, $1 \%$ 의 효모, $50 \%$ 의 물을 첨가하여 제조하였다. 전지분유 첨가구는 대조구와 동일한 방법으로 제조하되 수수량에 대하여 $1.0 \%$ 의 전지분유를 추가로 첨가하고, 물을 넣어 전체 수분함량이 $42 \%$ 되도록 제조하였다.

\section{이화학적 특성 분석}

수분함량은 적외선수분측정기(JP/FD-720, Kett engineering, Tokyo, Japan)를 이용하여 측정하였다. 술덧의 이화학적 특 성은 시료 $10 \mathrm{~g}$ 에 증류수 $1000 \mathrm{~mL}$ 를 정용하고 10 분간 교반 하였다. 이후 원심분리기(CR22N, Hitachi, Tokyo, Japan)로 $8,000 \mathrm{rpm}$ 에서 20 분간 원심 분리한 상등액을 국세청 주류분 석규정(NTS Liquor Licence Aid Center, 2010)을 준용하여 분석하였다. 알코올 함량은 알코올 측정계(DMA 101, Anton Paar Co., Graz, Austria)로 측정하였다. $\mathrm{pH}$ 는 시료 $100 \mathrm{~mL}$ 를 취하여 $\mathrm{pH}$ meter(Orion Star A214, Thermo scientific Co., Waltham, MA, USA)를 이용하여 3회 반복하였다. 산도 는 시료 $10 \mathrm{~mL}$ 를 취하여 $0.1 \%$ phenolphthalein(Sigma Chemical Co.) 지시약 2-3방울 떨어뜨린 다음 $0.1 \mathrm{~N} \mathrm{NaOH}$ (Samchun, Seoul, Korea)로 중화 적정하였으며, 소비된 용액 의 양을 산도로 표시하였다. 아미노산도는 시료 $10 \mathrm{~mL}$ 에 $0.1 \%$ phenolphthalein 시약을 2-3방울 넣고 $0.1 \mathrm{~N} \mathrm{NaOH}$ 용 액으로 시료가 담홍색이 될 때까지 중화시킨 후 중성 formalin용액 $5 \mathrm{~mL}$ 를 첨가하였다. 여기에 $0.1 \mathrm{~N} \mathrm{NaOH}$ 용액 으로 시료가 담홍색이 될 때까지 적정한 후 그 수치를 아미노 산도로 하였다.

환원당은 술덧 $10 \mathrm{~g}$ 에 증류수를 넣어 $1,000 \mathrm{~mL}$ 로 정용하 고 10 분간 교반한 다음, 원심분리 $(8,000 \mathrm{rpm}, 20$ 분 $)$ 한 상등액 을 시료로 사용하였다. 환원당 함량은 시료 $10 \mathrm{~mL}$ 를 Somogyi 변법(Hatanaka와 Kobara, 1980)에 준하여 정량한 후 glucose 함량으로 표시하였다.

\section{유기산 분석}

시료는 $0.45 \mu \mathrm{m}$ syringe filter(Nylon, Sartorius AG, Goettinge, Germany)로 여과하여 HPLC(LC-20A, Shimadzu Co., Kyoto, Japan)를 이용하였으며, post column 방법을 사용하여 분석 하였다. 분석용 column은 TSKgel ODS- $100 \mathrm{~V}(5 \mu \mathrm{m}, 4.6 \mathrm{~mm}$ $\mathrm{ID} \times 25.0 \mathrm{~cm}$, Tosoh, Tokyo, Japan)를 사용하였다. 이동상은 $8 \mathrm{mM}$ perchloric acid(Sigma Chemical Co.)를 이용하였으며, 유속은 $1.0 \mathrm{~mL} / \mathrm{min}$, 칼럼오븐의 온도는 $40^{\circ} \mathrm{C}$ 로 하였다. 분리 물은 반응용액 $0.2 \mathrm{mM}$ bromothymol blue(Sigma Chemical 
Co.), $15 \mathrm{mM} \mathrm{Na}_{2} \mathrm{HPO}_{4}$ (Sigma Chemical Co.), $7 \mathrm{mM} \mathrm{NaOH}$ 로 반응한 후 UV $440 \mathrm{~nm}$ 에서 검출하였다. 이때 반응용액의 유속은 $1.0 \mathrm{~mL} / \mathrm{min}$, 반응온도는 $25^{\circ} \mathrm{C}$ 로 하였다.

\section{증류}

증류방법은 전통적인 스팀을 이용한 방법과 마이크로웨이 브를 이용한 2가지 방법을 사용하였다. 스팀방식은 고체발효 술덧의 $5 \mathrm{~cm}$ 하부에 스팀을 직접 공급하여 술덧의 온도를 올려 증류하였다. 이때 스팀은 스팀발생기(Super boiler, Pyeonghwa Machinery Co., Daegu, Korea)를 사용하여 제조하였고, 스팀 의 온도는 $100^{\circ} \mathrm{C}$ 로 하였다. 마이크로웨이브를 이용한 방법은 대용량 마이크로웨이브 건조기(Microwave $10 \mathrm{Kw}, \mathrm{M} 2 \mathrm{Co}$, Gimhae, Korea)를 일부 변형하여 사용하였다. 즉, 증류액이 내부에서 외부로 나올 수 있도록 내벽에 직경 $1 \mathrm{~cm}$ 의 구멍을 내어 관을 연결하였다. 시료는 $5 \mathrm{~L}$ bottle(직경 $186 \mathrm{~mm}$, Schott Duran ${ }^{\circledR}$, Mainz, German)에 고체발효 술덧을 넣고 뚜 껑에 직경 $1 \mathrm{~cm}$ 실리콘관을 연결하여 외부로 통하는 관에 연결시켰다. 증류조건으로는 마이크로웨이브 출력을 $8 \mathrm{Kw}$ 로 하였고, 내부 공기의 대류온도는 $60^{\circ} \mathrm{C}$ 로 설정하였다. 스팀 과 마이크로웨브 방식 모두 고체발효 술덧 $1,000 \mathrm{~g}$ 을 이용하 여 증류하였으며, 냉각수의 온도는 $4^{\circ} \mathrm{C}$ 로 하였고, $50 \mathrm{~mL}$ 씩 분 획을 받아 분석시료로 사용하였다. 이때 술덧의 내부온도는 데이터 로거(UX120 4-channel analog logger, Onset HOBO Co., MA, USA)를 사용하여 모니터링하였다.

\section{휘발성 성분 분석}

휘발성 향기성분은 Gas chromatography(GC2010, Shimadzu Co., Kyoto, Japan)를 사용하여 분석하였다. 분석용 column 은 Fused silica capillary $30 \mathrm{~m} \times 0.32 \mathrm{~mm}$ id, $0.25 \mu \mathrm{m}$ thickness(Supelco, Bellefonte Co., PA, USA)을 사용하였다. Column oven의 온도는 $50^{\circ} \mathrm{C}(5$ 분 $), 5^{\circ} \mathrm{C} /$ 분 승온, $100^{\circ} \mathrm{C}$ (5분), $10^{\circ} \mathrm{C} /$ 분 승온, $220^{\circ} \mathrm{C}(10$ 분)로 프로그램하였다. 운반가스(질 소) 유속은 $24.2 \mathrm{~cm} /$ 초(linear velocity), split ratio는 50:1로 설정하였다. 주입기의 온도는 $250^{\circ} \mathrm{C}, \mathrm{FID}$ 검출기를 사용하였 으며, 온도는 $280^{\circ} \mathrm{C}$ 로 하였다. 시료는 여과(nylon, $0.22 \mu \mathrm{m}$ )
하여 사용하였다.

\section{통계처리}

통계는 SPSS 프로그램(Version 12.0, SPSS, Chicago, IL, USA)을 이용하여 분산분석(ANOVA) 후 유의차가 있는 항 목에 대하여는 Duncan's multilple range test로 $p<0.05$ 수준 에서 시료간의 유의차를 검정하였다.

\section{결과 및 고찰}

\section{술덧의 일반 특성}

발효가 종료된 고체발효 술덧의 일반성분을 Table 1에 나타 내었다. 수분함량은 대조군 $42.18 \%$, 전지분유 첨가군 $40.99 \%$ 로 처리구 사이에 큰 차이를 보이지 않았다. 알코올함량 역시 각각 $5.62 \%, 5.63 \%$ 로 유의적 차이가 없었다. 반면, 아미노산 도는 각각 0.32 와 0.77 로 전지분유의 첨가에 따라 2.4 배 증가 하였고, 환원당 함량도 $2.12 \%$ 에서 $6.09 \%$ 로 증가되었다. 이 러한 이유는 우유에 함유된 주된 영양성분은 lactose와 단백 질이나 실험에 사용된 효모는 lactose를 자화할 수 없는바 (Choi 등, 2004) 알코올 생산성에 영향 없이 술덧의 잔당으로 남은 것으로 해석된다. 한편, 우유에 포함된 단백질은 누룩의 산성 단백질 분해효소(In 등, 1995)에 의해 분해되면서 술덧 의 아미노산도를 높인 것으로 이해될 수 있다. 술덧에 포함된 아미노산은 증류 시 열에 의해서 휘발되지는 않으나, 산성 조 건에서 당과 결합하여 탄내성분인 furfural의 생성을 촉진 (Lee 등, 2014)시키기 때문에 관리가 요구된다.

발효효율 측면에서 술덧 $100 \mathrm{~g}$ 당 전분질 원료인 수수와 누룩의 양의 합은 $54.4 \mathrm{~g}$ 이며, 술덧의 알코올 함량이 약 $5.6 \%$ 이므로 곡물 1 톤당 순알코올 생성량은 $102.9 \mathrm{~L}$ 로 계산된다. 일반적으로 액상발효의 경우 곡물 1톤당 순알코올 생성량이 $400 \mathrm{~L}$ 이상이므로(Bea, 2001) 고체발효는 액상발효에 비하 여 발효효율이 4배 가량 낮은 것으로 나타났다.

\section{유기산}

고체발효 술덧의 유기산 함량은 Table 2와 같다. 유기산

Table 1. Effect of the addition of whole milk powder on the physicochemical properties of solid-state fermented mash

\begin{tabular}{ccccccc}
\hline Mash & $\begin{array}{c}\text { Moisture } \\
(\%)\end{array}$ & $\begin{array}{c}\text { Alcohol } \\
(\%)\end{array}$ & Amino acidity & pH & Acidity & $\begin{array}{c}\text { Reducing sugar } \\
(\%)\end{array}$ \\
\hline Not added & $42.18 \pm 0.09$ & $5.62 \pm 0.03$ & $0.32 \pm 0.00$ & $4.22 \pm 0.00$ & $0.40 \pm 0.02$ & $2.12 \pm 0.00$ \\
Added & $40.99 \pm 0.16$ & $5.63 \pm 0.03$ & $0.77 \pm 0.00$ & $4.67 \pm 0.00$ & $0.49 \pm 0.02$ & $6.09 \pm 0.01$ \\
t-value & $8.98^{* * *}$ & $-1.58^{\text {ns }}$ & $-405.17^{* * *}$ & $-96.87^{* * *}$ & $-6.36^{* *}$ & $-955.65^{* * *}$ \\
\hline
\end{tabular}

Values are mean $\pm \mathrm{SD}(\mathrm{n}=3) .{ }^{\mathrm{NS}}$ not significant, ${ }^{* *} \mathrm{p}<0.01,{ }^{* * *} \mathrm{p}<0.001$. 
Table 2. Effect of the addition of whole milk power on the contents of organic acids in solid-state fermented mash

\begin{tabular}{cccccc}
\hline \multirow{2}{*}{ Mash } & \multicolumn{4}{c}{ Organic acid concentration $(\mathrm{mg} / 100 \mathrm{~mL})$} \\
\cline { 2 - 6 } & Formic acid & Lactic acid & Acetic acid & Citric acid & Succinic acid \\
\hline Not added & $36.61 \pm 0.93^{\mathrm{D}}$ & $156.55 \pm 1.13^{\mathrm{A}}$ & $66.74 \pm 1.03^{\mathrm{C}}$ & $\mathrm{ND}$ & $97.72 \pm 0.86^{\mathrm{B}}$ \\
Added & $26.18 \pm 0.76^{\mathrm{D}}$ & $190.00 \pm 1.04^{\mathrm{A}}$ & $40.30 \pm 0.35^{\mathrm{C}}$ & $61.63 \pm 2.05^{\mathrm{B}}$ & $62.68 \pm 0.68^{\mathrm{B}}$ \\
t-value & $15.01^{* * *}$ & $-37.74^{* * *}$ & $42.29^{* * *}$ & $-52.15^{* * *}$ & $55.28^{* * *}$ \\
\hline
\end{tabular}

Values are mean $\pm \mathrm{SD}(\mathrm{n}=3) .{ }^{* * *} \mathrm{p}<0.001$.

함량의 총 함량은 대조군 $357.62 \mathrm{mg} / 100 \mathrm{~mL}$, 첨가군 380.79 $\mathrm{mg} / 100 \mathrm{~mL}$ 로 큰 차이를 보이지 않았다. 이는 분유 첨가구가 무첨가구에 비하여 lactic와 citric acid의 함량은 증가한 것 비해서 formic, acetic, succinic acid의 함량은 감소한 것에 따 른 것이다. 함량이 증가된 lactic acid와 citric acid는 우유에 이들 유기산이 각각 $97.90,132.99 \mathrm{mg} / 100 \mathrm{~mL}$ 정도 함유 (Dursun 등, 2017)되어 있어 분유 첨가에 따라 이들 함량이 증가한 것으로 풀이된다. 감소한 3 가지 유기산 역시 우유에 함유되어 있으나, 발효과정 중 대사되면서 그 양이 감소하였 을 것으로 추정된다. 즉, 술덧에 저급지방산의 첨가는 효모의 에스테르화 효소 발현량을 증가시켜 에스테르 화합물의 양을 증가시킨다(Shi 등, 2021). 우유의 지방산은 이들 효소의 활 성을 높여 ethyl acetate를 포함한 다른 에스테르 화합물의 증 가를 가져왔고(Table 3 ), 이로 인해 acetic acid의 함량은 감소 (Table 2)하였을 것으로 판단된다. 증류주에서 ethyl formate 와 ethyl succinate의 존재(Lee 등, 1994)는 그 외 유기산이 감소한 이유를 추론케 하나 확인이 필요하다. 발효과정 중 유 기산의 함량은 술덧의 $\mathrm{pH}$ 와 관련이 있고, 발효과정에서 생성 되는 것 이외에 증류과정 중 알코올과 에스테르 결합하여 생 성될 수 있고(Lee 등, 2007), 증류주의 향기를 부여한다.

\section{증류방법 별 증류효율 비교}

증류방식에 따른 시간별 알코올 유출동향을 Fig. 1에 나타 내었다. 증류시간은 마이크로웨이브 방식은 10 분이며, 스팀 방식은 45-75분으로 마이크로웨이브 방식이 4배 이상 빠르 게 증류되었다. 알코올 함량은 첫 번째 분획에서 높게 나타나 고 이후 급격하게 감소하였다. 마이크로웨이브 방식은 6개의 분획에 걸쳐 알코올이 유출되어 증류량은 $300 \mathrm{~mL}$ 이었고, 받 아진 증류액의 알코올 농도는 13.27-16.27\%로 나타났다. 반 면, 스팀방식은 4 개의 분획, $200 \mathrm{~mL}$ 가 받아졌으며, 알코올 함량은 17.71-27.17\%의 마이크로웨이브 방식보다 농축된 증 류액이 얻어졌다. 실험에 사용된 $1,000 \mathrm{~g}$ 의 술덧에는 약 $56 \mathrm{~mL}$ 의 순수한 알코올 함량을 가지고 있는 것으로 계산된다. 증류방 법별 순수한 알코올 회수량은 마이크로웨이브 방식이 39.82$48.57 \mathrm{~mL}$, 스팀방식은 $35.42-55.34 \mathrm{~mL}$ 이므로 두 가지 증류

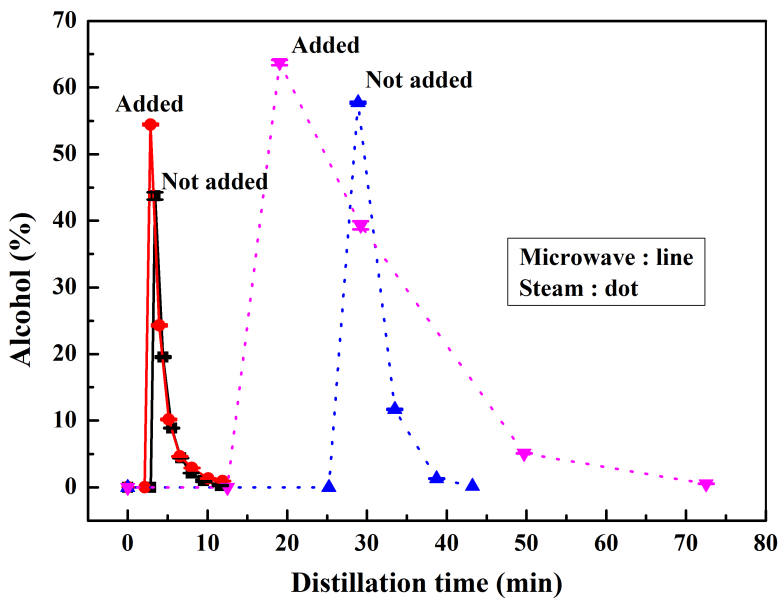

Fig. 1. Changes in the alcohol concentration as a function of the distillation time of various distillation methods.

방식에 따른 증류효율에 대한 큰 차이는 없었다.

마이크로웨브를 이용한 증류방법은 표면에 있는 알코올과 수분이 먼저 증발하고, 내부에 있는 알코올과 수분이 표면으 로 확산되어 증발되기 때문에 여러 분획에 걸쳐 알코올이 유 출되는 것으로 판단된다. 반면, 스팀방식은 술덧 하단에서 상 단 쪽으로 지속적으로 스팀이 공급되면서 물리적으로 알코올 이 외부로 유출되기 쉽고 알코올과 수분이 증발된 만큼 스팀 이 흡수되어 열전달이 원활했기 때문에 농축된 증류액을 얻 을 수 있었던 것으로 판단된다.

분유첨가에 따른 알코올 유출동향의 변화를 살펴보면 마 이크로웨이브나 스팀처리구 모두 첫 번째 분획에서 무첨가구 에 비하여 1.2 배 높은 알코올 함량을 보였고, 알코올 회수율 에 있어서도 마이크로웨이브 1.2배, 스팀 1.6배 높은 것으로 조사되었다. 다만, 유출속도에 있어 마이크로웨이브 방식은 큰 차이를 보이지 않았으나, 스팀방식의 경우 분유첨가에 따 라 유출속도가 느려졌다. 즉, 무첨가구는 25 분에 유출되기 시 작하여 45 분에 종료되어 유출시작부터 종료까지 20 분이 소 요된 반면, 분유첨가구는 13 분에 유출되기 시작하여 75 분에 유출이 종료되어 62 분이 소요되었다. 


\section{에스테르 화합물의 유출동향}

증류주의 특징을 부여하는 에스테르성분의 분획별 유출동 향을 Table 3에 나타내었다. Ethyl lactate를 제외하고 증류방 법에 관련 없이 첫 번째 분획에서 높은 비율로 유출되고, 이 후 급격히 감소하는 경향을 보였다. Ethyl lactate도 감소하기 는 하나, 감소비율이 낮아 모든 분획에서 비교적 높은 농도로 존재하고 있었다. 다만, ethyl lactate는 매우 약한향을 가지고 있어 품질에는 큰 영향을 미치지는 않는다(Lee 등, 2015). 이 러한 결과는 과일향의 강도가 첫 번째 분획에서 강하고, 이 후 급격히 감소하는 결과로 이어졌다(data not shwon).

전통적인 스팀증류법에 있어 분유첨가에 따른 에스테르 성 분의 함량을 살펴보면, ethyl acetate와 ethyl caproate의 성분변 화가 두드러지게 나타났다. 분유 무첨가구의 ethyl acetate 함 량의 평균값은 $1,061.70 \mathrm{mg} / \mathrm{L}$ 이었으나, 첨가구의 함량은 $2,107.07 \mathrm{mg} / \mathrm{L}$ 로 약 2 배 가량 증가하였다. Ethyl caproate의 함량의 평균값은 각각 12.27 과 $197.72 \mathrm{mg} / \mathrm{L}$ 로 16 배나 향상 되었다. Ethyl acetate는 과일향을 가지고 있는 성분으로서 쌀 소주에는 $25 \mathrm{mg} / \mathrm{L}$, 중국 고량주에는 $1,280 \mathrm{mg} / \mathrm{L}$ 정도 함유 되어 있는 것으로 알려져 있다(Lee 등, 2015). 분유를 첨가한 함량의 평균은 $2,104.07 \mathrm{mg} / \mathrm{L}$ 로 중국에서 생산되는 고량주 보다 1.6배 높은 ethyl acetate 함량을 유도하였다. 고량주의 특징적인 과일향을 부여하는 ethyl caproate의 역치는 ethyl acetate의 $1 / 100$ 인 $0.2 \mathrm{mg} / \mathrm{L}$ 로 매우 적은 양으로도 증류주에 큰 영향을 미친다(Lee 등, 2015). 쌀 소주에는 $1.3 \mathrm{mg} / \mathrm{L}(\mathrm{Yi}$ 등, 2010), 고량주의 종류에 따라 미량부터 $1,674.90 \mathrm{mg} / \mathrm{L}$ (Zhang 등, 2018)까지 다양하나, 마오타이주에서는 $170 \mathrm{mg} / \mathrm{L}$ 정도 함유되어 있는 것으로 조사되어 있다(Lee 등, 2015).

위에서 언급한 두가지 성분 이외에 고량주에 있어 중요한 성분이 파인애플 향을 가지고 있는 ethyl butylate이다(Gao 등, 2021). Ethyl butylate의 유출량의 총 함량은 무첨가구 $1,452.6 \mathrm{mg} / \mathrm{L}$, 첨가구 $1,630.12 \mathrm{mg} / \mathrm{L}$ 로 유사하여 분유가 함 량에 크게 영향을 미치지 못하는 것으로 조사되었다. Ethyl palmitate는 증류주의 감칠맛을 부여하는 성분으로 쌀 소주에 $0.4 \mathrm{mg} / \mathrm{L}$ 정도 함유되어 있는 것으로 알려져 있다(Lee 등, 2015). 분유 첨가에 따라 ethyl palmitate 함량의 평균값은 $19.59 \mathrm{mg} / \mathrm{L}$ 에서 $40.12 \mathrm{mg} / \mathrm{L}$ 로 2배 증가되었는데, 과다할 경 우 유취의 발생이나 백탁을 유도하기(Yi 등, 2010) 때문에 관 리가 요구된다.

마이크로웨이브 처리에 따른 변화를 살펴보면, 스팀증류 방식에 비해 ethyl caproate를 제외한 다른 에스테르성분의 유출이 감소되었다. 즉, 분유첨가구에 있어 ethyl acetate(끓 는점 $\left.76.8^{\circ} \mathrm{C}\right)$ 는 1.48 배, ethyl butyrate $\left(121.6^{\circ} \mathrm{C}\right)$ 는 1.50 배, ethyl lactate $\left(154.1^{\circ} \mathrm{C}\right)$ 는 1.91 배, ethyl palmitate $\left(191.1^{\circ} \mathrm{C}\right)$ 는 2.27 배로 끓는점 상승에 따라 유출량도 감소되었다. 그러나 ethyl caproate $\left(167.7^{\circ} \mathrm{C}\right)$ 는 1.46 배 증가되었다. 이에 대한 해 석은 보다 정밀한 접근이 필요하나, 결과적으로 마이크로웨 이브를 이용한 방법은 자극적인 잡향의 양은 줄이고, 과일향 의 강도는 증가시키는 것으로 나타났다.

\section{유기산류의 유출동향}

각 분획별 유기산 성분의 유출동향은 Table 4 와 같다. 대 부분의 유기산들이 분획별로 큰 증감이 없이 유사한 농도로 지속적으로 유출되었다. 전지분유 첨가에 따른 유기산류의 유출 총 함량을 살펴보면 acetic와 isovaleric acid는 각각 $1.38-4.30$ 배, 1.33-1.65배 감소한 반면, butyric, valeric, hexanoic acid는 증가하였다. 분획물의 유기산류는 술덧의 유기산 함 량과 관련이 있는 것으로 그 증감이유에 대해서는 위에서 언 급하였다.

검출된 유기산류 중 hexanoic acid를 제외하고는 자극적인 상한 버터 또는 땀 냄새 등의 불쾌취(Kim 등, 2010)를 가지 고 있어 함량의 증가할수록 품질에 영향을 미친다고 볼 수 있다. 따라서 특정분획에서 높은 함량으로 유출된다면 이들 분획을 제거시킴으로써 품질향상을 기대할 수 있으나, 증류 방법에 관련 없이 대부분의 분획에서 유사한 농도로 나오기 때문에 새로운 접근이 필요하다.

증류방법에 따른 유기산의 유출동향을 살펴보면, 무첨가 구의 유출량 합계는 서로 유사하였으나, 분유 첨가구에 있어 마이크로웨이브 증류법이 스팀 증류법보다 높은 함량으로 유 출되었다. 저급 유기산인 acetic acid와 butyric acid는 각각 4.79배, 1.58 배의 높은 비율로 높아졌고, 이보다 탄소수가 많 은 유기산은 소폭 증가되었다.

\section{Furfural의 유출동향}

증류주의 탄내성분인 furfural의 유출동향을 Table 5에 나 타내었다. 스팀과 마이크로웨이브 증류법 모두 분획의 증가에 따라 유출량도 증가되었다. 분유 무첨가구의 furfural 유출총 량은 $1,393.73 \mathrm{mg} / \mathrm{L}$ 이었으나, 분유 첨가는 $4,801.93 \mathrm{mg} / \mathrm{L}$ 로 3.45 배 증가되었다. 이는 분유 첨가에 따른 아미노산함량과 환원당량의 증가(Table 1)에 따른 것으로 해석된다. 일반적인 액체발효 증류식 소주에는 furfural이 $0.55 \mathrm{mg} / \mathrm{L}$ 이하(Lee 등 2015)로 존재하는데 비해서 고체발효 증류분획 혼합물에는 $464.59 \mathrm{mg} / \mathrm{L}$ 의 높은 함량으로 존재하고 있었으며, 분유첨가 에 따라 $1,600.70 \mathrm{mg} / \mathrm{L}$ 로 증가되었다.

증류방법 측면에서 마이크로웨이브를 이용한 경우, furfural 의 유출총량은 $4,586.31 \mathrm{mg} / \mathrm{L}$ 로 스팀방법보다 3.29 배 증가 되었다. 스팀방식과 마이크로웨이브방식의 증류과정 중 내부 술덧의 온도변화(Fig. 2)를 보면, 스팀방식은 $100^{\circ} \mathrm{C}$ 를 넘지 못하는데, 마이크로웨이브방식은 $300^{\circ} \mathrm{C}$ 이상으로 온도가 올 
Table 3. The content of ester compounds in the distilled fractions prepared by two different distillation methods

\begin{tabular}{|c|c|c|c|c|c|}
\hline \multirow{3}{*}{ Compounds } & \multirow{3}{*}{ Fraction No. } & \multicolumn{4}{|c|}{ Concentration $(\mathrm{mg} / \mathrm{L})$} \\
\hline & & \multicolumn{2}{|c|}{ Steam } & \multicolumn{2}{|c|}{ Microwave } \\
\hline & & Not added & Added $^{1)}$ & Not added & Added \\
\hline \multirow{6}{*}{ Ethyl acetate } & 1 & $3,126.96 \pm 14.70^{\mathrm{Ac}}$ & $6,047.59 \pm 6.94^{\mathrm{Aa}}$ & $3,047.04 \pm 8.25^{\mathrm{Ad}}$ & $3,689.02 \pm 17.24^{\mathrm{Ab}}$ \\
\hline & 2 & $58.13 \pm 0.25^{\mathrm{Bd}}$ & $264.62 \pm 2.08^{\mathrm{Bc}}$ & $384.53 \pm 2.06^{\mathrm{Bb}}$ & $453.84 \pm 5.47^{\mathrm{Ba}}$ \\
\hline & 3 & ND & ND & $66.54 \pm 0.44^{\mathrm{Cb}}$ & $114.21 \pm 1.46^{\mathrm{Ca}}$ \\
\hline & 4 & - & - & $17.27 \pm 0.58^{\mathrm{Db}}$ & $37.59 \pm 0.51^{\mathrm{Da}}$ \\
\hline & 5 & - & - & $6.53 \pm 0.05^{\mathrm{Ea}}$ & $4.69 \pm 0.30^{\mathrm{Eb}}$ \\
\hline & Total & $3,185.09 \pm 14.88^{\mathrm{d}}$ & $6,312.21 \pm 9.00^{\mathrm{a}}$ & $3,521.91 \pm 11.10^{\mathrm{c}}$ & $4,299.35 \pm 22.79^{b}$ \\
\hline \multirow{6}{*}{ Ethyl butyrate } & 1 & $1,128.85 \pm 9.11^{\mathrm{Ab}}$ & $1,352.39 \pm 1.79^{\mathrm{Aa}}$ & $834.85 \pm 4.14^{\mathrm{Ac}}$ & $844.84 \pm 8.56^{\mathrm{Ac}}$ \\
\hline & 2 & $279.70 \pm 1.12^{\mathrm{Ba}}$ & $247.28 \pm 3.67^{\mathrm{Bb}}$ & $282.70 \pm 4.68^{\mathrm{Ba}}$ & $127.89 \pm 1.69^{\mathrm{Bc}}$ \\
\hline & 3 & $43.61 \pm 2.06^{\mathrm{Cc}}$ & $30.45 \pm 0.93^{\mathrm{Cd}}$ & $97.55 \pm 0.66^{\mathrm{Ca}}$ & $55.75 \pm 3.11^{\mathrm{Cb}}$ \\
\hline & 4 & - & - & $58.39 \pm 0.73^{\mathrm{Da}}$ & $32.86 \pm 1.44^{\mathrm{Db}}$ \\
\hline & 5 & - & - & $29.41 \pm 0.45^{\mathrm{Ea}}$ & $24.57 \pm 0.83^{\mathrm{Ea}}$ \\
\hline & Total & $1,452.16 \pm 12.07^{\mathrm{b}}$ & $1,630.12 \pm 6.18^{\mathrm{a}}$ & $1,303.22 \pm 10.39^{c}$ & $1,086.36 \pm 15.18^{d}$ \\
\hline \multirow{6}{*}{ Ethyl caproate } & 1 & $36.81 \pm 0.68^{\mathrm{Ac}}$ & $428.12 \pm 0.33^{\mathrm{Ab}}$ & $31.67 \pm 0.44^{\mathrm{Ad}}$ & $760.70 \pm 0.90^{\mathrm{Aa}}$ \\
\hline & 2 & $\mathrm{ND}$ & $137.13 \pm 1.74^{\mathrm{Ba}}$ & ND & $55.89 \pm 0.94^{\mathrm{Bb}}$ \\
\hline & 3 & ND & $27.92 \pm 0.35^{\mathrm{Ca}}$ & ND & $27.75 \pm 0.64^{\mathrm{Ca}}$ \\
\hline & 4 & - & - & ND & $23.57 \pm 0.51^{\mathrm{Da}}$ \\
\hline & 5 & - & - & ND & ND \\
\hline & Total & $36.81 \pm 0.68^{\mathrm{c}}$ & $593.17 \pm 2.38^{\mathrm{b}}$ & $31.67 \pm 0.44^{\mathrm{d}}$ & $867.91 \pm 2.79^{\mathrm{a}}$ \\
\hline \multirow{6}{*}{ Ethyl lactate } & 1 & $1,148.86 \pm 7.46^{\mathrm{Ab}}$ & $1,356.59 \pm 2.35^{\mathrm{Aa}}$ & $579.46 \pm 13.33^{\mathrm{Ac}}$ & $415.05 \pm 8.98^{\mathrm{Ad}}$ \\
\hline & 2 & $1,075.75 \pm 13.47^{\mathrm{Ba}}$ & $919.82 \pm 4.39^{\mathrm{Bb}}$ & $502.41 \pm 2.39^{\mathrm{Bc}}$ & $401.17 \pm 7.95^{\mathrm{Bd}}$ \\
\hline & 3 & $562.13 \pm 14.01^{\mathrm{Ca}}$ & $266.76 \pm 3.68^{\mathrm{Cc}}$ & $301.61 \pm 3.96^{\mathrm{Cb}}$ & $287.43 \pm 4.06^{\mathrm{Cb}}$ \\
\hline & 4 & - & - & $233.06 \pm 9.30^{\mathrm{Da}}$ & $145.77 \pm 2.73^{\mathrm{Db}}$ \\
\hline & 5 & - & - & $112.71 \pm 2.22^{\mathrm{Ea}}$ & $83.43 \pm 1.70^{\mathrm{Eb}}$ \\
\hline & Total & $2,786.73 \pm 34.61^{\mathrm{a}}$ & $2,543.17 \pm 9.89^{b}$ & $1,726.77 \pm 30.64^{\mathrm{c}}$ & $1,332.85 \pm 24.88^{\mathrm{d}}$ \\
\hline \multirow{6}{*}{ Ethyl palmitate } & 1 & $58.77 \pm 0.41^{\mathrm{Ab}}$ & $120.36 \pm 0.54^{\mathrm{Aa}}$ & $51.07 \pm 0.22^{\mathrm{Ad}}$ & $52.80 \pm 0.33^{\mathrm{Ac}}$ \\
\hline & 2 & ND & ND & ND & ND \\
\hline & 3 & ND & ND & ND & ND \\
\hline & 4 & - & - & ND & ND \\
\hline & 5 & - & - & $\mathrm{ND}$ & ND \\
\hline & Total & $58.77 \pm 0.41^{\mathrm{b}}$ & $120.36 \pm 0.54^{\mathrm{a}}$ & $51.07 \pm 0.22^{\mathrm{d}}$ & $52.80 \pm 0.33^{\mathrm{c}}$ \\
\hline
\end{tabular}

${ }^{1)}$ Whole milk power was added during solid-state fermentation.

All values are mean \pm SD $(n=3)$. ND, not detected.

Different uppercase and lowercase superscripted letters show statistically significant differences $(\mathrm{p}<0.05)$ for each compound in the rows and the columns, respectively. 
Table 4. Changes in the content of the organic acid compounds in the distilled fractions obtained by using two different distillation methods

\begin{tabular}{|c|c|c|c|c|c|}
\hline \multirow{3}{*}{ Compounds } & \multirow{3}{*}{ Fraction No. } & \multicolumn{4}{|c|}{ Concentration $(\mathrm{mg} / \mathrm{L})$} \\
\hline & & \multicolumn{2}{|c|}{ Steam } & \multicolumn{2}{|c|}{ Microwave } \\
\hline & & Not added & Added $^{1)}$ & Not added & Added \\
\hline \multirow{6}{*}{ Acetic acid } & 1 & $256.19 \pm 5.86^{\mathrm{Cb}}$ & $63.37 \pm 2.56^{\mathrm{Cd}}$ & $415.30 \pm 4.50^{\mathrm{Da}}$ & $211.49 \pm 7.83^{\mathrm{Ec}}$ \\
\hline & 2 & $673.46 \pm 3.87^{\mathrm{Ba}}$ & $207.57 \pm 5.76^{\mathrm{Bd}}$ & $586.36 \pm 2.94^{\mathrm{Bb}}$ & $296.77 \pm 0.76^{\mathrm{Dc}}$ \\
\hline & 3 & $775.25 \pm 2.02^{\mathrm{Aa}}$ & $126.05 \pm 0.80^{\mathrm{Ad}}$ & $537.17 \pm 8.22^{\mathrm{Cb}}$ & $405.58 \pm 0.95^{\mathrm{Cc}}$ \\
\hline & 4 & - & - & $662.26 \pm 1.79^{\mathrm{Aa}}$ & $476.56 \pm 0.60^{\mathrm{Bb}}$ \\
\hline & 5 & - & - & $437.54 \pm 1.43^{\mathrm{Db}}$ & $511.71 \pm 2.41^{\mathrm{Aa}}$ \\
\hline & Total & $1,704.90 \pm 11.03^{\mathrm{c}}$ & $396.93 \pm 8.62^{d}$ & $2,638.62 \pm 18.74^{\mathrm{a}}$ & $1,902.11 \pm 11.92^{\mathrm{b}}$ \\
\hline \multirow{6}{*}{ Propionic acid } & 1 & ND & ND & ND & ND \\
\hline & 2 & $94.80 \pm 0.27^{\mathrm{Bb}}$ & ND & $27.87 \pm 0.94^{\mathrm{Aa}}$ & ND \\
\hline & 3 & $120.06 \pm 6.05^{\mathrm{Aa}}$ & ND & $4.36 \pm 0.47^{\mathrm{Bb}}$ & ND \\
\hline & 4 & - & - & $4.02 \pm 0.07^{\mathrm{Bb}}$ & ND \\
\hline & 5 & - & - & ND & ND \\
\hline & Total & $214.87 \pm 6.29^{\mathrm{a}}$ & - & $36.24 \pm 1.44^{\mathrm{b}}$ & - \\
\hline \multirow{6}{*}{ Butyric acid } & 1 & $54.44 \pm 1.31^{\mathrm{Ac}}$ & $287.32 \pm 0.19^{\mathrm{Aa}}$ & ND & $259.03 \pm 6.72^{\mathrm{Bb}}$ \\
\hline & 2 & $57.17 \pm 0.06^{\mathrm{Ab}}$ & $298.07 \pm 9.12^{\mathrm{Aa}}$ & ND & $283.48 \pm 12.89^{\mathrm{Aa}}$ \\
\hline & 3 & $52.55 \pm 1.06^{\mathrm{Ac}}$ & $227.63 \pm 4.55^{\mathrm{Bb}}$ & ND & $285.09 \pm 3.25^{\mathrm{Aa}}$ \\
\hline & 4 & - & - & ND & $256.09 \pm 3.58^{\mathrm{Bb}}$ \\
\hline & 5 & - & - & ND & $199.25 \pm 4.74^{\mathrm{Cc}}$ \\
\hline & Total & $164.16 \pm 2.42^{\mathrm{c}}$ & $813.02 \pm 12.96^{\mathrm{b}}$ & - & $1,279.94 \pm 30.33^{\mathrm{a}}$ \\
\hline \multirow{6}{*}{ Isovaleric acid } & 1 & $78.89 \pm 0.75^{\mathrm{Cc}}$ & $53.28 \pm 0.25^{\mathrm{Bb}}$ & $63.19 \pm 0.65^{\mathrm{Aa}}$ & $53.83 \pm 0.52^{\mathrm{Aa}}$ \\
\hline & 2 & $84.42 \pm 0.06^{\mathrm{Ba}}$ & $68.80 \pm 0.66^{\mathrm{Ab}}$ & $59.78 \pm 0.26^{\mathrm{Bc}}$ & $54.36 \pm 0.47^{\mathrm{Ad}}$ \\
\hline & 3 & $123.50 \pm 0.78^{\mathrm{Aa}}$ & $52.37 \pm 0.48^{\mathrm{Bc}}$ & $55.82 \pm 2.26^{\mathrm{Cb}}$ & $51.60 \pm 0.61^{\mathrm{Bc}}$ \\
\hline & 4 & - & - & $51.32 \pm 1.05^{\mathrm{Dd}}$ & $48.99 \pm 0.59^{\mathrm{Cc}}$ \\
\hline & 5 & - & - & $46.91 \pm 0.52^{\mathrm{Ea}}$ & ND \\
\hline & Total & $286.81 \pm 1.81^{\mathrm{a}}$ & $174.45 \pm 1.38^{\mathrm{d}}$ & $277.01 \pm 4.57^{\mathrm{b}}$ & $208.78 \pm 2.10^{\mathrm{c}}$ \\
\hline \multirow{6}{*}{ Valeric acid } & 1 & ND & $50.84 \pm 0.58^{\mathrm{Aa}}$ & ND & ND \\
\hline & 2 & ND & $52.90 \pm 0.34^{\mathrm{Aa}}$ & ND & ND \\
\hline & 3 & ND & ND & ND & ND \\
\hline & 4 & - & - & ND & ND \\
\hline & 5 & - & - & ND & ND \\
\hline & Total & - & $103.74 \pm 0.92^{\mathrm{a}}$ & - & - \\
\hline
\end{tabular}


(continued)

\begin{tabular}{|c|c|c|c|c|c|}
\hline \multirow{3}{*}{ Compounds } & \multirow{3}{*}{ Fraction No. } & \multicolumn{4}{|c|}{ Concentration $(\mathrm{mg} / \mathrm{L})$} \\
\hline & & \multicolumn{2}{|c|}{ Steam } & \multicolumn{2}{|c|}{ Microwave } \\
\hline & & Not added & Added $^{1)}$ & Not added & Added \\
\hline \multirow{6}{*}{ Hexanoic acid } & 1 & ND & $175.06 \pm 3.25^{\mathrm{Aa}}$ & ND & $128.39 \pm 1.81^{\mathrm{Ab}}$ \\
\hline & 2 & $69.64 \pm 0.14^{\mathrm{Ac}}$ & $163.61 \pm 2.42^{\mathrm{Ba}}$ & ND & $114.82 \pm 4.08^{\mathrm{Bb}}$ \\
\hline & 3 & $69.01 \pm 0.30^{\mathrm{Aa}}$ & $114.64 \pm 4.60^{\mathrm{Cc}}$ & ND & $112.80 \pm 3.04^{\mathrm{Bb}}$ \\
\hline & 4 & - & - & ND & $104.99 \pm 3.09^{\mathrm{Ca}}$ \\
\hline & 5 & - & - & ND & $91.43 \pm 3.15^{\mathrm{Da}}$ \\
\hline & Total & $138.65 \pm 0.44^{\mathrm{c}}$ & $453.31 \pm 9.80^{\mathrm{b}}$ & - & $550.43 \pm 14.90^{\mathrm{a}}$ \\
\hline
\end{tabular}

${ }^{1)}$ Whole milk power was added during solid-state fermentation.

All values are mean \pm SD $(n=3)$.

Different uppercase and lowercase superscripted letters show statistically significant differences $(p<0.05)$ for each compound in the rows and the columns, respectively.

Table 5. Changes in the content of furfural in the distilled fractions obtained by using two different distillation methods

\begin{tabular}{|c|c|c|c|c|}
\hline \multirow{3}{*}{ Fraction No. } & \multicolumn{4}{|c|}{ Concentration (mg/L) } \\
\hline & \multicolumn{2}{|c|}{ Steam } & \multicolumn{2}{|c|}{ Microwave } \\
\hline & Not added & Added $^{1)}$ & Not added & Added \\
\hline 1 & $151.37 \pm 1.44^{\mathrm{Cd}}$ & $703.68 \pm 2.80^{\mathrm{Cb}}$ & $618.77 \pm 0.70^{\mathrm{Dc}}$ & $1,224.82 \pm 3.60^{\mathrm{Ea}}$ \\
\hline 2 & $570.76 \pm 1.34^{\mathrm{Bd}}$ & $1,982.98 \pm 6.01^{\mathrm{Ba}}$ & $751.55 \pm 3.89^{\mathrm{Cc}}$ & $1,524.25 \pm 6.02^{\mathrm{Db}}$ \\
\hline 3 & $671.60 \pm 3.45^{\mathrm{Ad}}$ & $2,115.43 \pm 8.16^{\mathrm{Aa}}$ & $1,094.90 \pm 12.23^{\mathrm{Ac}}$ & $1,558.86 \pm 2.49^{\mathrm{Cb}}$ \\
\hline 4 & ND & ND & $1,016.25 \pm 5.64^{\mathrm{Bb}}$ & $1,844.15 \pm 9.00^{\mathrm{Ba}}$ \\
\hline 5 & ND & ND & $1,104.84 \pm 5.45^{\mathrm{Ab}}$ & $2,202.96 \pm 3.37^{\mathrm{Aa}}$ \\
\hline Total & $1,393.73 \pm 6.22^{d}$ & $4,801.90 \pm 16.66^{\mathrm{b}}$ & $4,586.31 \pm 27.17^{\mathrm{c}}$ & $8,355.04 \pm 23.47^{\mathrm{a}}$ \\
\hline
\end{tabular}

${ }^{1)}$ Whole milk power was added during solid-state fermentation.

All values are mean \pm SD $(n=3)$.

Different uppercase and lowercase superscripted letters show statistically significant differences $(\mathrm{p}<0.05)$ for each compound in the rows and the columns, respectively.

(A)

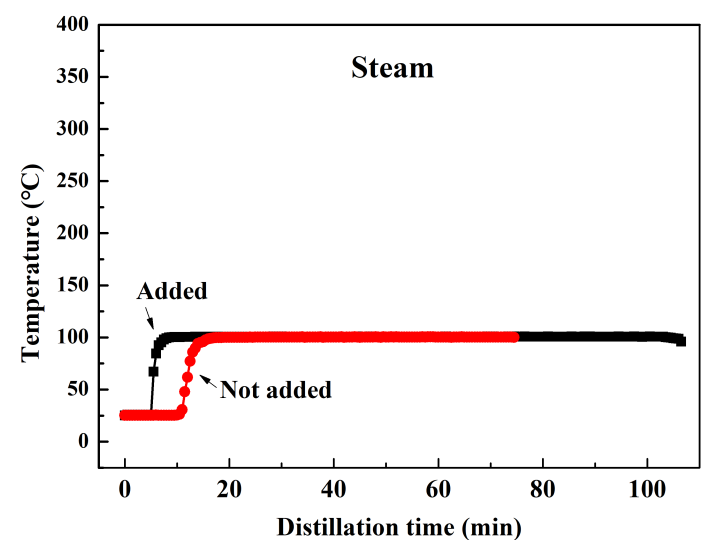

(B)

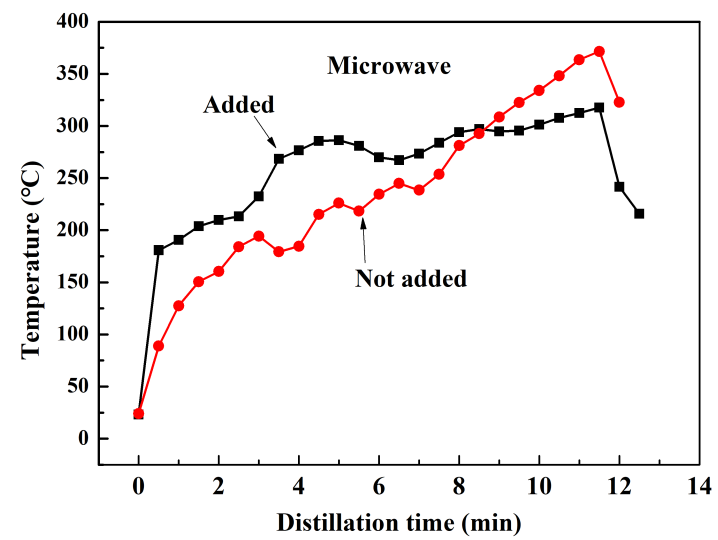

Fig. 2. Changes in the internal temperature of the mash as a function of the distillation time of various distillation methods. 
라가면서 furfural의 유출량을 증대시킨 것으로 이해된다.

현재까지의 결과를 요약하면 고체발효물에 분유를 첨가하 면 방향성을 지닌 에스테르 화합물의 증대를 가져왔으나, 더 불어 탄내 성분인 furfural 함량도 증가되었다. 마이크로웨이 브를 이용한 증류방식은 스팀방식에 비하여 증류시간이 단축 되고, ethyl caproate 성분의 유출이 증대되었으나 furfural 함 량의 증가를 가져왔다. 앞으로 생산성을 높이면서 이취를 제 어할 수 있는 후속 연구가 필요하다고 생각된다.

\section{요 약}

고체발효 증류주의 향을 증진시키고자 분유를 첨가하여 발효하고 증류방법을 달리하여 발효물의 성분유출동향에 대 하여 평가하였다. 전지분유 첨가에 따른 알코올 생성량 변화 는 없었으나, 아미노산도와 환원당 함량이 증가되었고, formic, acetic, succinic acid의 함량은 감소되었다. 마이크로웨이브 를 이용한 증류법이 스팀증류법보다 증류 속도는 4 배 이상 빨랐으나, 넓은 범위로 알코올이 유출되면서 분획의 개수는 더욱 많았다. 전지분유 첨가에 따라 분획물에서 ethyl acetate 와 ethyl caproate의 함량이 각각 2배, 16-27배 이상 유출되었 고, 휘발성 유기산 중 butyric, valeric, hexanoic acid의 함량도 증가되었다. 또한, 증류주의 가열취 성분인 furfural의 함량은 $1,393.73 \mathrm{mg} / \mathrm{L}$ 에서 $4,801.93 \mathrm{mg} / \mathrm{L}$ 로 3.45 배 증가되었다. 마 이크로웨이브 증류방법은 스팀증류법에 비해 ethyl caproate의 유출총량을 1.46 배 증가시켰으나, 발효물의 내부온도가 30 $0^{\circ} \mathrm{C}$ 이상 올라가면서 furfural의 유출량도 3.29 배 증가시켰다.

\section{감사의 글}

본 연구는 농촌진흥청 공동연구사업(과제번호: PJ015294) 의 지원에 의해 수행되었습니다.

\section{Conflict of interests}

The authors declare no potential conflict of interest.

\section{ORCID}

Je Young Shin https://orcid.org/0000-0001-8359-7241

Han-Seok Choi https://orcid.org/0000-0001-6792-5620

\section{References}

Ahn BH, im HR, Kim JH, Kan HR. Brewing yeast
Saccharomyces cerevisiae 54-3 and brewed alcohol made there with. Korea, Patent No. 20130016006 (2014)

Bea SM. Distilled Soju Manufacturing Technology. Bae Sang-myeon Liquor Research Institute Co., Seoul, Korea, p 228 (2012)

Choi HS, Kim EG, Kang JE, Choi JH, Yeo SH. Effect of varying the amount of water added on the characteristics of mash fermented using modified Nuruk for distilledSoju production. Korean J Food Preserv, 21, 908-916 (2004)

Dursun A, Guler Z, Sekerli YE. Characterization of volatile compounds and organic acids in ultra-high-temperature milk packaged in tetra brik cartons. Int J Food Prop, 20, 1511-1521 (2017)

Hatanaka C, Kobara Y. Determination of glucose by a modification of Somogyi-Nelson method. Agric Biol Chem, 44, 2943-2949 (1980)

In HY, Lee TS, Lee DS, Noh BS. Volatile components and fusel oils of sojues and mashes brewed by Korean traditional method. Korean J Food Sci Technol, 27, 235-240 (1995)

Kim GR, Yoon SR, Lee JH, Yeo SH, Jeong YJ, Yoon KY, Kwon JH. Physicochemical properties of and volatile components in commercial fruit vinegars. Korean J Food Preserv, 17, 616-624 (2010)

Kim WK, Lee SJ. Changes in volatile compounds in ricebased distilled Soju aged in different types of containers. Korean J Food Sci Technol, 51, 543-550 (2019)

Korea Customs Service (KCS), Statistics on Trade, Daejeon: Import and Export Trade Statistics. https://unipass.customs. go.kr/ets/hmpg/openTRS0107001Q.do?hsSgn=22089060 00\&hsSgnLen=10. (accessed September 2021)

Lee BS, Park SK. Volatile aromatic compounds and fermentation properties of fermented milk with buckwheat. Korean J Food Sci Technol, 45, 267-273 (2013)

Lee DH, Lee YS, Cho CH, Park IT, Kim JH, Ahn BH. The qualities of liquor distilled from Ipguk (koji) or Nuruk under reduced or atmospheric pressure. Korean J Food Sci Technol, 46, 25-32 (2014)

Lee DH, Jung JW, Lee YS, Seo JS, Park IT, Kim TW, Kim $\mathrm{JH}, \mathrm{Ahn} \mathrm{BH}$. Quality characteristics of distilled liquor produced using Ipguk (Koji) during aging. Korean J Food Sci Technol, 46, 694-701 (2014)

Lee DS, Park HS, Kim K, Lee TS, Noh BS. Determination 
and multivariate analysis of flavour components in the Korean folk sojues using GC-MS. Korean J Food Sci Technol, 26, 750-758 (1994)

Lee HS, Lee TS, Noh BS. Volatile flavor components in the mashes of Takju prepared using different yeasts. Korean J Food Sci Technol, 39, 593-599 (2007)

Lee JG, Moon SH, Bae KH, Kim JH, Choi HS, Kim TW, Jung C. Distilled Spirits. Gwangmunkag Co., Seoul, Korea, p 384-391 (2015)

Lin CJ, Chang DM, Hsieh C, Lee JF. A study of the relationships among the composition and sensory evaluation of Chinese spirits and consumer behavior. J Humanities Soc Sci, 2, 25-35 (2006)

Ministry of Agriculture Food and Rural Affairs (MAFRA), Korea Rural-Fisheries \& Food Trade Corp. 2020 Liquor Market Trend Report, Gwacheon, Korea, p 9-10 (2021) Ministry for food agricultural forestry and fisheries (MIFFAF). Food, Agricultural, Forestry and Fisheries Statistical Yearbook. Gwacheon, Korea, p 102 (2012)

NTS Liquors Licence Aid Center. Analysis of Alcoholic Beverages. National Tax Service, Seoul, Korea, p 79 (2010)

Ryu LH, Kim YM. Esterification of alcohols with organic acids during distilled spirit distillation. Korean J Food Nutr, 15, 295-299 (2002)

Shi W, Li J, Chen Y, Chen Y, Guo X, Xiao D. Enhancement of C6-C10 fatty acid ethyl esters production in Saccharomyces cerevisiae CA by metabolic engineering. LWT, 145, 111496 (2021)

Yan S, Dong D. Improvement of caproic acid production in a Clostridium kluyveri H068 and Methanogen 166 coculture fermentation system. Amb Express, 8, 1-13 (2018)

Yi HC, Moon SH, Park JS, Jung JW, Hwang KT. Volatile compounds in liquor distilled from mash produced using Koji or Nuruk under reduced or atmospheric pressure. J Korean Soc Food Sci Nutr, 39, 880-886 (2010)

Yoon KH, Kim K, Lee GH. Enzymatic synthesis of ethyl butyrate using ester synthetase derived from banana peel and pineapple peel. J Korean Soc Food Sci Nutr, 46, 1122-1127 (2017)

Zhang T, Ni H, LI T, Zhang LZ, Huang Gl, Li QB. Analysis of the aroma and volatile compounds in kinmen sorghum liquor. Modern Food Sci Technol, 34, 258-265 (2018) 